ISSN 0103-9954

\title{
CRESCIMENTO INICIAL DE Amburana cearensis (Allem.) A. C. Smith EM SISTEMA AGROFLORESTAL NO SEMIÁRIDO BRASILEIRO
}

\author{
INITIAL GROWTH OF Amburana cearensis (Allem.) A. C. Smith IN AN AGROFORESTRY SYSTEM \\ IN THE BRAZILIAN SEMIARID
}

João Vianey Fernandes Pimentel ${ }^{1}$ Hugo Orlando Carvallo Guerra ${ }^{2}$

\begin{abstract}
RESUMO
O cumaru (Amburana cearensis (Allem.) A. C. Smith) é uma espécie nativa do semiárido brasileiro que apresenta múltiplas utilidades como madeira de boa qualidade e contém princípio ativo que pode ser utilizado nas indústrias alimentícias, de perfume e na produção de medicamentos. É, também, planta forrageira e melífera. As respostas do cumaru à adubação orgânica e cobertura morta do solo, insumos oriundos e ciclados dentro do próprio agroecossistema, são ainda pouco conhecidas. Para isto, um experimento foi montado visando estudar o comportamento das mudas em um sistema agroflorestal (em consórcio com milho e feijão), testando-se diferentes níveis de matéria orgânica $(0,15$ e $30 \mathrm{~L}$ de esterco na cova), com e sem cobertura morta no solo. Avaliou-se a altura de plantas, diâmetro caulinar, número de folhas, área foliar e sobrevivência das plantas no campo após um ano de plantio. O cumaru, no sistema agroflorestal estudado, mostrou-se indiferente ao uso de cobertura morta e adaptado às condições de baixa matéria orgânica no solo, obtendo-se o maior crescimento na ausência de matéria orgânica (esterco).
\end{abstract}

Palavras-chave: cumaru; adubação orgânica; cobertura do solo.

\begin{abstract}
Amburana cearensis (Allem.) A. C. Smith is a Brazilian semiarid region native plant. It presents good quality wood, contains an active ingredient that can be used for food, perfume and medicine production and it is also a forage and a melifera plant. The responses of the studied species to organic fertilizer and mulch, inputs produced and cycled within its ecosystem are still unknown. For this, an experiment was conducted to study the behavior of seedlings in an agroforestry system intercropped with maize and beans, testing different levels of organic matter $(0,15$ and $30 \mathrm{~L}$ of manure) with and without soil mulch. It was evaluated the plant height, stem diameter, leaf number, leaf area and the survival of plants in the field one year after planting. The performance of $A$. cearensis was indifferent to the use of mulch and well adapted to low soil organic matter conditions, obtaining the largest growth in the absence of organic matter.
\end{abstract}

Keywords: cumaru; organic fertilization; mulching.

\section{INTRODUÇÃO}

O Semiárido Brasileiro é caracterizado pela distribuição irregular das chuvas, associadas a elevadas temperaturas, baixa umidade relativa do ar, solos rasos e eventualmente ventos fortes, cujos efeitos sobre os ecossistemas são intensificados pelo manejo inadequado do solo e da água. Em geral, os sistemas de produção, praticados na Região, quer pela agricultura tradicional, quer pela moderna, não apresentam sustentabilidade (retorno às gerações atuais, sem o comprometimento das gerações

1 Engenheiro Agrônomo, Dr., Professor de Meio Ambiente e Agroecologia, Instituto Federal de Educação, Ciência e Tecnologia do Rio Grande do Norte, Câmpus Ipanguaçu, RN 118, S/N, Povoado Base Física, CEP 59508-000, Ipanguaçu (RN), Brasil. vianeypim@gmail.com

2 Engenheiro Agrônomo, PhD., Professor do Curso de Pós-graduação em Engenharia Agrícola, Universidade Federal de Campina Grande, Coordenação de Pós-graduação em Engenharia Agrícola, Av. Aprígio Veloso, 882, Bodocongó, CEP 58429-140, Campina Grande (PB), Brasil. hugo_carvallo@hotmail.com 
futuras). São adotadas tecnologias, geralmente agressivas ao meio ambiente, resultando na redução drástica da biodiversidade, tanto nas áreas de cultivo, como nas de pastagens, na exposição do solo à erosão, na sedimentação das fontes e mananciais, e no quase completo desaparecimento da fauna pela destruição de seus habitats. Sistemas agrícolas tradicionais, predominantes em toda a Região, incluindo desmatamentos e queimadas repetidas ao longo de quase quatro séculos, induziram intensa degradação ambiental, com os processos de desertificação patentes em extensas áreas dos sertões nordestinos. Os rendimentos da produção agrícola e pecuária alcançaram índices muito aquém dos necessários à geração de uma renda que garanta a qualidade de vida das populações sertanejas, intensificando o êxodo rural (ARAÚJO FILHO, 2006).

Os sistemas de produção agroflorestais (SAFs) foram desenvolvidos em resposta às pressões por produção de alimentos para a população humana. Integram a exploração de lenhosas perenes nativas com pastos ou outras espécies de valor econômico, a fim de garantir a estabilidade e elevar a produtividade da terra, diversificar a produção, melhorar a fertilidade do solo e aumentar a oferta de produtos de boa qualidade (ARAÚJO FILHO et al., 2010). A maior vantagem dos sistemas agroflorestais é, precisamente, sua capacidade de manter bons níveis de produção em longo prazo e melhorar a produtividade de forma sustentável. Essa vantagem deve-se, principalmente, ao fato de que muitas árvores e arbustos utilizados nos SAFs têm, entre outras funções, a capacidade de adubar, proteger e conservar o solo. Os SAFs são quase sempre manejados sem aplicação de defensivos agrícolas químicos ou requerem quantidades mínimas dessas substâncias. Os efeitos negativos sobre o meio ambiente são, portanto, mínimos. Outro aspecto importante é que a associação entre árvores e arbustos, nas culturas agrícolas e nas pastagens, contribui para a conservação dos rios e cursos de água (DUBOIS et al., 1996 e COUTO et al., 2011).

Uma destas árvores é o cumaru (Amburana cearensis) que se trata de uma espécie nativa de múltiplas utilidades, sua madeira de boa qualidade, fácil de trabalhar e com aroma agradável, é vendida no comércio sob o nome de cerejeira. Suas raízes, entrecasca e sementes produzem a cumarina, princípio ativo que, além de ser utilizado como fixador nas indústrias de perfume, nas indústrias alimentícias (doces e biscoitos), de cigarros e tabacos, é utilizado na produção de medicamentos como anti-inflamatório e broncodilatador, a exemplo do xarope de cumaru ou lambedores caseiros, de largo uso popular, e de eficácia comprovada cientificamente (CANUTO, 2008). Pela sua beleza, a árvore pode ser usada como ornamental em projetos paisagísticos. Para recuperação de solos e restauração florestal de áreas degradadas é utilizada tanto na fase inicial como nas fases posteriores do reflorestamento, inclusive como mata ciliar, em locais com inundações periódicas de curta duração (MAIA, 2004). Em sistemas agroflorestais pode ser usada como quebra-ventos e faixas arbóreas entre plantações. Como forrageira suas folhas e vagens são consumidas pelos caprinos, tanto verdes como secas, e pelos bovinos depois de secas. É também de grande importância para a apicultura e meliponicultura pelo fato de fornecer néctar na estação seca do ano, figurando entre as 18 espécies mais utilizadas pelas abelhas nativas para coleta de pólen e/ou néctar e como local de nidificação, além da utilização da sua madeira na construção de colmeias (MARINHO et al., 2002).

Além dos fatores atribuídos ao cultivo mínimo do solo, podem restringir a implantação de espécies florestais: o deficit hídrico, o estresse provocado pelo calor e o choque térmico, o vento, a salinidade e a deficiência de oxigênio (TAIZ e ZEIGER, 2004). Da mesma forma, a nutrição inadequada, a competição com ervas espontâneas, as pragas e as doenças e os danos mecânicos ou por animais também podem estressar as mudas, causando sérios prejuízos na implantação da cultura. Considerando a inexistência de trabalhos com respeito à resposta do cumaru a qualquer manejo agrícola ou agroflorestal no bioma Caatinga, pesquisas necessitam ser realizadas para validação do cultivo da planta, constituindo-se em possíveis opções ecológicas, econômicas e socialmente viáveis para as condições edafoclimáticas do Trópico Semiárido do Nordeste Brasileiro. Como a aclimatação das mudas de espécies nativas é um dos atributos de qualidade que contribui para diminuição dos replantios possibilitando a formação de florestas mais homogêneas (LOPES, 2009; TATAGIBA et al., 2007), mesmo depois do plantio tornam-se interessantes os estudos da influência do esterco e da cobertura morta, que podem propiciar tolerâncias aos fatores que causam prejuízos econômicos. Pretende-se, portanto, avaliar a resposta das plantas ao uso da adubação orgânica, com adição de esterco 
nas covas, por ocasião do plantio das mudas, e ao uso da cobertura morta do solo.

\section{MATERIAL E MÉTODOS}

O experimento foi conduzido no Núcleo de Educação Ambiental (NEA), vinculado ao Instituto Brasileiro de Meio Ambiente (IBAMA) no Município de Quixeramobim, localizado na área do Sertão Central do Estado do Ceará. Está encravado na região semiárida, apresentando coordenadas geográficas com $5^{\circ} 12^{\prime} 08^{\prime \prime}$ de latitude Sul, 39 $17^{\prime} 11$ ' de longitude Oeste e uma altitude de 196 m acima do nível do mar. O clima, segundo a classificação de Köppen é do tipo BShw' - semiárido com curta estação chuvosa no verão-outono, com concentração das chuvas nos meses de março e abril. A pluviosidade média normal do município é

TABELA 1: Atributos químicos do solo da área experimental.

TABLE 1: Soil chemical attributes of the experimental area.

\begin{tabular}{ccc}
\hline Atributos químicos (complexos sortivos) & Unidade & Amostra \\
\hline Cálcio $\left(\mathrm{Ca}^{++}\right)$ & $\mathrm{mmol}_{\mathrm{c}} \mathrm{kg}^{-1}$ & 83,2 \\
Magnésio $\left(\mathrm{Mg}^{++}\right)$ & $\mathrm{mol}_{\mathrm{c}} \mathrm{kg}^{-1}$ & 64,9 \\
Sódio $\left(\mathrm{Na}^{+}\right)$ & $\mathrm{mmol}_{\mathrm{c}} \mathrm{kg}^{-1}$ & 1,6 \\
Potássio $\left(\mathrm{K}^{+}\right)$ & $\mathrm{mmol}_{\mathrm{c}} \mathrm{kg}^{-1}$ & 6,45 \\
$\mathrm{H}^{+}+\mathrm{Al}^{3+}$ & $\mathrm{mmol}_{\mathrm{c}} \mathrm{kg}^{-1}$ & 10,2 \\
Soma das bases (S) & $\mathrm{mmol}_{\mathrm{c}} \mathrm{kg}^{-1}$ & 156,15 \\
Totais (T) & $\mathrm{mmol} \mathrm{kg}^{1}$ & 166,3 \\
Saturação por bases $(\mathrm{V})$ & $\%$ & 91,5 \\
Carbonato de cálcio qualitativo & & Ausência \\
Matéria orgânica & - & 20,75 \\
Carbono orgânico (C) & $\mathrm{g} \mathrm{kg}^{-1}$ & 12,05 \\
Nitrogênio (N) & $\mathrm{g} \mathrm{kg}^{-1}$ & 0,12 \\
Fósforo Assimilável & $\mathrm{g} \mathrm{kg}^{-1}$ & 0,37 \\
pH em água (1:2,5) & $\mathrm{mg} \mathrm{kg}^{-1}$ & 6,76 \\
Condutividade Elétrica (suspensão solo-água) & - & 0,25
\end{tabular}

Em que: ${ }^{1} \mathrm{~T}$ é a capacidade de troca de cátions, que corresponde à soma das bases trocáveis mais a acidez potencial (T $\left.=\mathrm{S}+\mathrm{H}^{+}+\mathrm{Al}^{3+}\right)$. ${ }^{2}$ Indica se há ou não a presença do carbonato de cálcio. Método volumétrico com titulação pelo ácido sulfúrico. Obs.: Análises realizadas no Laboratório de Irrigação e Salinidade da Engenharia Agrícola, do Centro de Tecnologia e Recursos Naturais da UFCG.

TABELA 2: Características do esterco.

TABLE 2: Characteristics of manure.

\begin{tabular}{ccc}
\hline Resultados Analíticos & Unidade & Valor \\
\hline Nitrogênio total & $\mathrm{g} \mathrm{kg}^{-1}$ & 21,3 \\
$\mathrm{P}_{2} \mathrm{O}_{5}$ & $\mathrm{~g} \mathrm{~kg}^{-1}$ & 21,8 \\
$\mathrm{~K}_{2} \mathrm{O}$ & $\mathrm{g} \mathrm{kg}^{-1}$ & 54,9 \\
Cálcio & $\mathrm{g} \mathrm{kg}^{-1}$ & 25,3 \\
Magnésio & $\mathrm{g} \mathrm{kg}^{-1}$ & 11,1 \\
Ferro & $\mathrm{mg} \mathrm{kg}^{-1}$ & 7.708 \\
Cobre & $\mathrm{mg} \mathrm{kg}^{-1}$ & 123,4 \\
Zinco & $\mathrm{mg} \mathrm{kg}^{-1}$ & 187,2 \\
Manganês & $\mathrm{mg} \mathrm{kg}^{-1}$ & 21,4 \\
\hline
\end{tabular}

Obs: Análises realizadas no Laboratório de Solos/Água da UFC/FUNCEME, do Centro de Ciências Agrárias da UFC. 
de $858,5 \mathrm{~mm}$ (INMET, 1992). A temperatura varia entre $22,2^{\circ} \mathrm{C}$ e $32,5^{\circ} \mathrm{C}$.

Preparou-se a área, utilizando-se a mecanização, através de um gradeamento, e abertura de covas para o plantio das mudas e confecção de microbacias ao pé da planta (diâmetro de 60 a 80 $\mathrm{cm}$ ) para contenção da água das chuvas (captação in situ), dado que este experimento não recebeu irrigação senão que unicamente a precipitação. A área foi dividida em quatro blocos, nos quais foram implantados os tratamentos de matéria orgânica no solo e presença e ausência de cobertura morta. As mudas de cumaru foram plantadas em linhas, com espaçamento entre plantas de 4 metros e de 10 metros entre linhas, sendo as mudas distribuídas no campo, conforme o sorteio dos tratamentos. Nas bordaduras, acrescentou-se mais uma linha de cumaru (bordadura simples) e além das espécies nativas e exóticas existentes no entorno, foram plantadas outras margeando a área, a exemplo de jucá (Caesalpinia ferrea Mart. ex Tul.), gliricídea (Gliricidea sepium (Jacq.) Steud), sabiá (Mimosa caesalpiniaefolia Benth) e juazeiro (Ziziphus joazeiro Mart.).

O experimento foi conduzido entre fevereiro de 2009 e maio de 2010 incluindo consórcio de duas safras de milho e feijão em plantio simultâneo, nas entrelinhas de cumaru, na época chuvosa do ano (de fevereiro a maio), com espaçamento médio de $1,0 \mathrm{~m} \times 0,5 \mathrm{~m}$ em fileiras duplas alternadas.

As mudas foram produzidas em viveiro, com quantidades diferenciadas de esterco $(25 \%$, $50 \%$ e $75 \%$ do volume total do solo), sendo suas raízes cuidadosamente retiradas do vaso de 5,95 litros, destorroadas e lavadas antes do transplantio para o campo, visando à eliminação de possíveis interferências futuras do substrato.

Foram realizadas duas amostragens do solo no campo, antes do plantio do cumaru em consórcio no sistema agroflorestal. Também foi analisado o esterco bovino utilizado. Os resultados da análise química do solo são apresentados na Tabela 1 . Na
Tabela 2 encontram-se os resultados da análise do esterco.

As mudas foram distribuídas nas respectivas covas $(0,40 \mathrm{~m} \times 0,40 \mathrm{~m} \times 0,40 \mathrm{~m})$, conforme os tratamentos de aplicação de esterco bovino na cova: N1 (sem esterco), N2 (15 litros de esterco) e N3 (30 litros de esterco). A cobertura morta foi aplicada através dos tratamentos presença e ausência de cobertura morta (CC e SC, respectivamente). A cobertura morta utilizada foi oriunda da coleta de folhas e ramos finos já em processo de decomposição sobre o solo, em uma área de caatinga com predominância de jurema-preta (Mimosa sp.) e marmeleiro (Croton $s p$.). Esta cobertura foi aplicada ao redor das plantas, formando uma camada de aproximadamente $2 \mathrm{~cm}$. Os tratamentos foram replicados em 4 blocos.

Um ano após o transplante das mudas no campo, foram avaliadas as variáveis altura da planta, diâmetro da planta, sobrevivência das plantas, número de folhas e área foliar. A altura da planta foi medida em centímetros, entre a superfície do solo sem cobertura e a parte mais alta da planta. $\mathrm{O}$ diâmetro foi aferido utilizando-se paquímetro com as leituras realizadas a uma altura de $5 \mathrm{~cm}$ em relação ao nível do solo. Na determinação do número de folhas por planta, foram consideradas apenas as folhas completamente abertas, com pelo menos $3 \mathrm{~cm}$ de comprimento (nervura principal). Já para a área foliar considerou-se o comprimento e largura da folha, utilizando-se o fator de correção de 0,4818, determinado em Pimentel (2011), para folhas de cumaru, com metodologia semelhante à de Pinto et al. (2007) para folhas de maniçoba. E para a sobrevivência das plantas contou-se as plantas efetivamente vivas após um ano do plantio.

As precipitações pluviométricas que ocorreram na área, durante a realização do experimento, foram aferidas com o uso de um pluviômetro (Tabela 3).

O delineamento estatístico foi em blocos casualizados (3 níveis de esterco x 2 coberturas de solo x 4 repetições). Utilizou-se o software

TABELA 3: Precipitações pluviométricas na área do sistema agroflorestal com Amburana cearensis.

TABLE 3: Rainfall in the area of agroforestry system with Amburana cearensis.

\begin{tabular}{cccccccccccccc}
\hline Anos & \multicolumn{11}{c}{ Precipitações $(\mathrm{mm})$} \\
\hline & Jan. & Fev. & Mar. & Abr. & Mai. & Jun. & Jul. & Ago. & Set. & Out. & Nov. & Dez. \\
2009 & 0 & 87 & 197 & 418 & 228 & 85 & 67 & 40 & 0 & 0 & 0 & 7 \\
2010 & 76 & 19 & & & & & & & & & & \\
\hline
\end{tabular}


ASSISTAT, em conformidade com Silva e Azevedo (2006, 2009). Os dados foram submetidos à análise de variância ao nível de $5 \%$ e $1 \%$ de probabilidade de erro, pelo teste F, conforme Ferreira (2000), e as médias foram comparadas pelo teste de Tukey ao nível de $5 \%$ de probabilidade.

\section{RESULTADOS E DISCUSSÃO}

Ocorreu efeito significativo do esterco, mas não da cobertura morta sobre a altura de plantas, um ano após o transplantio (Tabela 4), embora em trabalho anterior, Pimentel e Guerra (2011), com mudas aos 147 dias após a semeadura (DAS), tenham encontrado efeito positivo da cobertura morta sobre a altura de plantas. Mesmo que a cobertura morta possa ter promovido provável efeito benéfico sobre a temperatura do solo e disponibilidade de água, as plantas jovens de cumaru, após o transplante, pelas características adaptativas da espécie (perdendo ou ganhando folhas em função do fotoperíodo e estação chuvosa do ano), foram indiferentes ao uso da cobertura morta para altura de plantas, provavelmente pelo fato desta variável ter sido influenciada pelo número de folhas.

Constatou-se que houve influência negativa do esterco sobre o crescimento do cumaru, aos 365 dias após o transplante (DAT), tornando-se mais altas as mudas que não receberam esterco na cova, por ocasião do transplante das mudas, provavelmente, pelo fato da concentração de sais e nutrientes presentes no esterco terem atingido níveis tóxicos para o cumaru, pelos dados de salinidade encontrados em amostras da mistura solo e esterco utilizados como substratos na formação das mudas, atingindo $10,93 \mathrm{dS} \mathrm{m}^{-1}$ nos tratamentos com maior quantidade de esterco. No entanto, este não foi o comportamento observado em outras fases de cultivo (formação de mudas), pois, conforme Pimentel e Guerra (2011), houve efeito benéfico do esterco aos 147 DAS em mudas de cumaru, mesmo com os níveis de salinidade elevados no substrato. Na região do Vale do São Francisco, Angelim et al. (2007) avaliaram a altura de plântulas de Amburana cearensis a partir dos 23 dias de idade durante 150 dias, em medições mensais. Os tratamentos utilizados foram: (T1)

TABELA 4: Análises de variância e médias para a altura de plantas, com relação à quantidade de esterco (N) aplicada em fundação, à cobertura morta no solo (CC) e suas interações, nas plantas jovens de Amburana cearensis em sistema agroflorestal, aos 365 dias após o transplante - DAT.

TABLE 4: Analysis of variance and means for plant height in relation to the amount of manure $(\mathrm{N})$ applied to the foundation, the mulch into the soil (CC) and their interactions, in young plants of Amburana cearensis agro-forestry system, to 365 days after the transplant - DAT.

\begin{tabular}{lcc}
\hline \multicolumn{1}{c}{ Fonte de Variação } & Graus de Liberdade & Quadrados Médios \\
\hline Esterco (N) & 2 & $960,24 * *$ \\
Cobertura morta (C) & 1 & $5,06 \mathrm{~ns}$ \\
Esterco X Cob. Morta (N X C) & 2 & $109,77 \mathrm{~ns}$ \\
Blocos & 3 & $59,57 \mathrm{~ns}$ \\
Resíduo & 15 & 35,55 \\
Coeficiente de Variação & & 23,29 \\
\hline$\quad$ Níveis de esterco (N) & Médias $(\mathrm{cm})$ \\
\hline N1 $(0-$ sem esterco na cova) & $37,86 \mathrm{a}$ \\
N2 (15 litros por cova) & $22,20 \mathrm{~b}$ \\
N3 (30 litros por cova) & & $16,76 \mathrm{~b}$ \\
\hline \multicolumn{1}{c}{ Cobertura morta $(\mathrm{C})$} & & $26,06 \mathrm{a}$ \\
\hline CC $($ com cobertura) & & $25,14 \mathrm{a}$ \\
SC (sem cobertura) & & 25,60
\end{tabular}

Em que: ** significativo ao nível de $1 \%$ de probabilidade $(\mathrm{p}<0,01)$; ${ }^{\text {ns }}$ não significativo $(\mathrm{p} \geq 0,05)$ pelo teste de $\mathrm{F}$. As médias seguidas pela mesma letra não diferem estatisticamente entre si pelo Teste de Tukey ao nível de $5 \%$ de probabilidade. 
$100 \%$ solo; (T2) $75 \%$ solo, $25 \%$ esterco humificado; (T3) $50 \%$ solo, $50 \%$ esterco humificado; (T4) $25 \%$ solo, $75 \%$ esterco humificado. A altura de plantas até os 90 dias foi uniforme para todos os tratamentos; entretanto, aos 120 dias, verificouse que, em geral, o substrato de crescimento das plantas que apresentou melhor resultado foi aquele no qual não se aplicou adubo orgânico, à semelhança do que se observou neste experimento. Os referidos autores atribuíram tal resposta às características adaptativas da espécie aos solos de baixa fertilidade. Este comportamento é completamente atípico para as plantas tradicionalmente cultivadas, merecendo maiores estudos e investigações na fisiologia das plantas xerófilas.

Da mesma forma que para altura de plantas, o diâmetro caulinar foi influenciado apenas pelos níveis de esterco no solo. Um ano após o transplante, as plantas jovens de cumaru que não receberam esterco na cova apresentaram maiores diâmetros caulinares, sendo diferentes estatisticamente dos diâmetros das plantas que receberam 15 ou 30 litros de esterco por cova, ao transplantio (Tabela 5).

Cruz et al. (2011) estudando macronutrientes na produção de mudas de canafístula (Peltophorum dubium (Spreng.) Taub.) em Argissolo Vermelho Amarelo da Região da Zona da Mata - MG não encontraram diferenças significativas para diâmetros caulinares, em doses crescentes de nitrogênio, afirmando que a espécie estudada apresenta baixa exigência e, apesar dos teores de $\mathrm{N}$ no solo serem originalmente baixos, encontravam-se próximos do ideal para a espécie, ou seja, a dose ideal está entre o teor original do solo e a menor dose testada. Fato semelhante pode ter acontecido com as dosagens de esterco testadas neste experimento.

Ocorreu influência apenas do esterco sobre o número de folhas das plantas jovens de cumaru, 365 dias após o transplante (Tabela 6). A ausência de resposta do número de folhas com relação à cobertura morta, diz respeito ao comportamento fenológico da espécie, que perde as folhas de forma irregular, durante a estação seca do ano, em função

TABELA 5: Análise de variância para o diâmetro caulinar, com relação à quantidade de esterco (N) aplicada em fundação, à cobertura morta no solo (CC) e suas interações, nas plantas jovens de Amburana cearensis em sistema agroflorestal, aos 365 dias após o transplante.

TABLE 5: Analysis of variance for the stem diameter, in relation with the amount of manure $(\mathrm{N})$ applied to the foundation, the mulch into the soil (CC) and their interactions, in young plants of Amburana cearensis agro-forestry system, to 365 days after transplantation.

\begin{tabular}{lcc}
\hline \multicolumn{1}{c}{ Fonte de Variação } & Graus de Liberdade & Quadrados Médios \\
\hline Esterco $(\mathrm{N})$ & 2 & $12,79^{* *}$ \\
\hline \multicolumn{1}{c}{ Cobertura morta (C) } & 1 & $0,80^{\mathrm{ns}}$ \\
\hline Esterco X Cob. Morta (N X C) & 2 & $1,84^{\text {ns }}$ \\
Blocos & 3 & $1,18^{\text {ns }}$ \\
Resíduo & 15 & 0,63 \\
Coeficiente de Variação & & 23,30 \\
\hline
\end{tabular}

Coeficiente de Variação

Médias $(\mathrm{mm})$

\begin{tabular}{lc}
\hline N1 $(0-$ sem esterco na cova) & $4,78 \mathrm{a}$ \\
N2 (15 litros por cova) & $3,14 \mathrm{~b}$ \\
N3 (30 litros por cova) & $2,29 \mathrm{~b}$ \\
\hline
\end{tabular}

Cobertura morta (C)

\begin{tabular}{cc}
\hline CC (com cobertura) & $3,58 \mathrm{a}$ \\
$\mathrm{SC}$ (sem cobertura) & $3,22 \mathrm{a}$ \\
\hline \multicolumn{1}{c|}{ Média geral $(\mathrm{mm})$} & 3,40
\end{tabular}

Em que: **significativo ao nível de $1 \%$ de probabilidade $(\mathrm{p}<0,01)$; ${ }^{\text {ns }}$ não significativo $(\mathrm{p} \geq 0,05)$ pelo teste de $\mathrm{F}$. As médias seguidas pela mesma letra não diferem estatisticamente entre si pelo Teste de Tukey ao nível de $5 \%$ de probabilidade. 
TABELA 6: Análises de variância para o número de folhas, com relação à quantidade de esterco $(\mathrm{N})$ aplicada em fundação, à cobertura morta no solo (CC) e suas interações, nas plantas jovens de Amburana cearensis em sistema agroflorestal, aos 365 dias após o transplante.

TABLE 6: Analysis of variance for the number of leaves in relation to the amount of manure $(\mathrm{N})$ applied to the foundation, the mulch into the soil (CC) and their interactions, in young plants of Amburana cearensis agro-forestry system, to 365 days after the transplanting.

\begin{tabular}{lcc}
\hline \multicolumn{1}{c}{ Fonte de Variação } & Graus de Liberdade & Quadrados Médios \\
\hline Esterco ( N) & 2 & $0,033^{* *}$ \\
Cobertura morta (C) & 1 & $0,002^{\mathrm{ns}}$ \\
Esterco X Cob. Morta (N X C) & 2 & $0,004^{\mathrm{ns}}$ \\
Blocos & 3 & $0,005^{\mathrm{ns}}$ \\
Resíduo & 15 & 0,003 \\
Coeficiente de Variação & & 5,11 \\
\hline \multicolumn{1}{c}{ Níveis de esterco (N) } & Médias sem transformação (NF) \\
\hline N1 (0 - sem esterco na cova) & 4,23 a \\
N2 (15 litros por cova) & $1,20 \mathrm{~b}$ \\
N3 (30 litros por cova) & $0,73 \mathrm{~b}$ \\
\hline \multicolumn{1}{c}{ Cobertura morta (C) } & \\
\hline CC (com cobertura) & $1,87 \mathrm{a}$ \\
SC (sem cobertura) & $2,23 \mathrm{a}$ \\
\hline \multicolumn{1}{c}{ Média geral $(\mathrm{cm})$} & 2,05 \\
\hline
\end{tabular}

Em que: ${ }^{* *}$ significativo ao nível de $1 \%$ de probabilidade $(\mathrm{p}<0,01) ;{ }^{\text {ns }}$ não significativo $(\mathrm{p} \geq 0,05)$ pelo teste de $\mathrm{F}$. Dados transformados por $\mathrm{x}=\log (x+10)$. As médias seguidas pela mesma letra não diferem estatisticamente entre si pelo Teste de Tukey ao nível de $5 \%$ de probabilidade.

do fotoperíodo.

O número de folhas das plantas que não receberam esterco no transplante é superior ao das que receberam 15 e 30 litros por cova.

Com relação à área foliar ocorreu influência apenas do esterco, destacando-se a área foliar das plantas que não receberam esterco por ocasião do transplante. As demais, que receberam 15 e 30 litros por cova, apresentaram, aos 365 DAT, área foliar bem menor (Tabela 7). Estas grandes diferenças na área foliar justificam-se pelos mesmos motivos expostos para altura de plantas e número de folhas, que expressam a mesma resposta.

Com o aumento do esterco aplicado nas covas durante o transplante, houve diminuição na sobrevivência das plantas no campo, sendo a ausência do esterco favorável à sobrevivência (Tabela 8). Esta resposta pode estar associada tanto à salinidade do esterco como à elevada concentração de nutrientes, em relação à baixa exigência da espécie, facilmente atingindo concentrações tóxicas.

A cobertura morta apresentou efeito desfavorável apenas nas plantas que receberam maior quantidade de esterco na cova (30 L), sendo indiferente nos demais tratamentos (Tabela 8). Isto ocorre, muito provavelmente, pelo fato do cumaru ser espécie nativa, bastante adaptada às condições do semiárido, com maior ocorrência em solos de baixo teor de nutrientes, tendo a matéria orgânica contribuído para concentrações tóxicas, desfavoráveis à sobrevivência das plantas. A cobertura morta agiu preservando a matéria orgânica e nutrientes (evitando perdas por volatilização de nitrogênio) em camadas superficiais e profundas do solo, contribuindo para a toxicidade dos nutrientes, em tratamentos nos quais a matéria orgânica se apresentava em maiores quantidades.

Angelim et al. (2007) também atribuíram o melhor crescimento e desenvolvimento morfológico das mudas de cumaru em solos sem aplicação de matéria orgânica ao fato da espécie estar bem adaptada às condições adversas como falta de água e também à reduzida concentração de matéria orgânica, de macro e de micronutrientes no solo. Lucena et al. (2006) pesquisando diferentes substratos com matéria orgânica na germinação 
TABELA 7: Análises de variância para a área foliar, com relação à quantidade de esterco $(\mathrm{N})$ aplicada em fundação, à cobertura morta no solo (CC) e suas interações, nas plantas jovens de Amburana cearensis em sistema agroflorestal, aos 365 dias após o transplante.

TABLE 7: Analysis of variance for leaf area in relation to the amount of manure (N) applied to the foundation, the mulch into the soil (CC) and their interactions, in young plants of Amburana cearensis agro-forestry system, to 365 days after transplantation.

\begin{tabular}{lcc}
\hline \multicolumn{1}{c}{ Fonte de Variação } & Graus de Liberdade & Quadrados Médios \\
\hline Esterco (N) & 2 & $0,722 * *$ \\
Cobertura morta (C) & 1 & $0,028^{\mathrm{ns}}$ \\
Esterco X Cob. Morta (N X C) & 2 & $0,048^{\mathrm{ns}}$ \\
Blocos & 3 & $0,154^{\mathrm{ns}}$ \\
Resíduo & 15 & 0,071 \\
Coeficiente de Variação & & 16,01 \\
\hline \multicolumn{1}{c}{ Níveis de esterco (N) } & Médias sem transformação $\left(\mathrm{cm}^{2}\right)$ \\
\hline N1 (0 - sem esterco na cova) & 101,21 a \\
N2 (15 litros por cova) & $27,28 \mathrm{~b}$ \\
N3 (30 litros por cova) & $8,92 \mathrm{~b}$ \\
\hline \multicolumn{1}{c}{ Cobertura morta $(\mathrm{C})$} & \\
\hline CC (com cobertura) & $48,47 \mathrm{a}$ \\
SC (sem cobertura) & $43,14 \mathrm{a}$ \\
\hline \multicolumn{1}{c}{ Média geral $\left(\mathrm{m}^{2}\right)$} & 45,80 \\
\hline
\end{tabular}

Em que: **significativo ao nível de $1 \%$ de probabilidade $(\mathrm{p}<0,01)$; ${ }^{\text {ns }}$ não significativo $(\mathrm{p} \geq 0,05)$ pelo teste de $\mathrm{F}$. Dados transformados por $\mathrm{x}=\log (x+10)$. As médias seguidas pela mesma letra não diferem estatisticamente entre si no Teste de Tukey ao nível de $5 \%$ de probabilidade.

TABELA 8: Análises de variância para a sobrevivência das plantas de Amburana cearensis no campo, com relação à quantidade de esterco $(\mathrm{N})$ aplicada em fundação, à cobertura morta no solo $(\mathrm{CC}) \mathrm{e}$ suas interações em sistema agroflorestal, aos 365 dias após o transplante.

TABLE 8: Analysis of variance for the survival of plants Amburana cearensis in the field, in relation with the amount of manure $(\mathrm{N})$ applied to the foundation, the mulch into the soil (CC) and their interactions in agroforestry, to 365 days after transplantation.

\begin{tabular}{|c|c|c|}
\hline Fonte de Variação & Graus de Liberdade & Quadrados Médios \\
\hline Esterco $(\mathrm{N})$ & 2 & $0,187 *$ \\
\hline Cobertura morta $(\mathrm{C})$ & 1 & $0,007^{\text {ns }}$ \\
\hline Esterco X Cob. Morta (N X C) & 2 & $0,127 *$ \\
\hline Blocos & 3 & $0,022^{\text {ns }}$ \\
\hline Resíduo & 15 & 0,032 \\
\hline Coeficiente de Variação & & 26,65 \\
\hline \multicolumn{3}{|c|}{ Médias de sobrevivência de plantas (escala de 0 a 1 ) } \\
\hline $\mathrm{N} / \mathrm{C}$ & $\mathrm{SC}$ & Médias \\
\hline N1 & $0,80 \mathrm{aA}$ & $0,80 \mathrm{a}$ \\
\hline $\mathrm{N} 2$ & $0,60 \mathrm{aA}$ & $0,70 \mathrm{ab}$ \\
\hline N3 & $0,65 \mathrm{aA}$ & $0,50 \mathrm{~b}$ \\
\hline Médias & $0,68 \mathrm{~A}$ & 0,67 \\
\hline
\end{tabular}

Em que: *significativo ao nível de $5 \%$ de probabilidade $(\mathrm{p}<0,05)$; ${ }^{\text {ns }}$ não significativo $(\mathrm{p} \geq 0,05)$ pelo teste de $\mathrm{F}$. As médias seguidas pela mesma letra não diferem estatisticamente entre si no Teste de Tukey ao nível de $5 \%$ de probabilidade. Atribuiu-se o valor 1 (um) para a sobrevivência e 0 (zero) para plantas ausentes ou mortas. 
de espécies florestais concluíram que o substrato constituído com esterco de galinha (que apresenta maior teor de nitrogênio, em relação às demais fontes de matéria orgânica testadas) produz nas essências florestais estudadas a menor germinação, e que embora o substrato composto por solo arenoso mais esterco de galinha, propiciou o maior índice de germinação nas sementes do Tambor ou Tamboril (Enterolobium contortisiliquum (Vell.) Morong.), as mudas obtidas foram de menor tamanho e vigor.

\section{CONCLUSÕES}

A altura da planta, o diâmetro caulinar, o número de folhas, a área foliar e a sobrevivência das plantas de cumaru no sistema agroflorestal (cumaru + milho + feijão) foram influenciados inversamente pela adição de esterco, demonstrando a adaptabilidade da espécie à falta de matéria orgânica no solo. Entretanto, a presença ou ausência da cobertura do solo não influenciou o desenvolvimento das plantas até um ano de idade.

\section{REFERÊNCIAS BIBLIOGRÁFICAS}

ARAÚJO FILHO, J. A. O bioma caatinga. In: FALCÃO SOBRINHO, J. \& FALCÃO, C.L.C. Semi-Árido: diversidades, fragilidades e potencialidades. Sobral: Sobral Gráfica, 2006, p. 49-70.

ARAÚJO FILHO, J. A. et al. Sistema de Produção Agrossilvipastoril no Semiárido do Ceará. In: 2nd International Conference: Climate, Sustainability and Development in Semi-arid Regions, 2. 2010, Fortaleza. Anais... ICID: Fortaleza, 2010.

ANGELIM, A.E.S. et al. Germinação e Aspectos Morfológicos de Plantas de Umburana de Cheiro (Amburana cearensis) Encontradas na Região do Vale do São Francisco. Revista Brasileira de Biociências, Porto Alegre, v. 5, supl. 2, p. 10621064, jul. 2007.

CANUTO, K. M. Aspectos Químicos do Estudo Interdisciplinar (Química-AgronomiaFarmacologia) de Amburana cearensis A.C. Smith . 2007. 313 f. Tese (Doutorado em Química Orgânica) - Universidade Federal do Ceará, Fortaleza, 2008.

COUTO, R. et al. Sistema agroflorestal como manejo sustentável na fazenda Kamurá em São Geraldo do Araguaia estado do Pará. In: I Jornada de Iniciação Científica e de Extensão da FACTO 2011/01, Palmas. Anais... Faculdade Católica do
Tocantins: Palmas, 2011.

CRUZ, C. A. F. e et al. Macronutrientes na produção de mudas de canafístula em Argissolo Vermelho Amarelo da Região da Zona da Mata, MG. Ciência Florestal, Santa Maria, v. 21, n. 3, p. 445-457, jul./set., 2011.

DINIZ, J. A. Sistema de manejo do solo e níveis de nitrogênio: Efeito sobre o estabelecimento, crescimento, desenvolvimento e rendimento do algodoeiro herbáceo. 1996. 98p. Universidade Federal da Paraíba UFPB, Dissertação (Mestrado em Manejo de Solo e água) - Universidade Federal da Paraíba, 1996.

DUBOIS, J. C. L. et al. Manual Agroflorestal para a Amazônia, v. 1, Rio de Janeiro: REBRAF, 1996. $228 \mathrm{p}$.

FERREIRA, P. V. Estatística experimental aplicada à agronomia. 2. ed. Maceió: EDUFAL, 2000. $421 \mathrm{p}$.

INSTITUTO NACIONAL DE METEOROLOGIA (INMET). Normais climatológicas (1961-1990), Brasília, DF: INMET,1992. 155 p.

LOPES, J. L. W. et al. Influência dos fatores bióticos e abióticos na sobrevivência de eucalipto em função do solo e do manejo de viveiro. Biotemas, Florianópolis, v. 22, n. 2, p. 29-38, jun. 2009.

LUCENA, A. M. A. et al. Germinação de essências florestais em substratos fertilizados com matéria orgânica. Revista Principia, João Pessoa, n. 13, p. 27-33, abr. 2006.

MAIA, G. N. Caatinga: árvores e arbustos e suas utilidades. São Paulo: Leitura e Arte, 2004.

MARINHO, I. V. et al. Espécies Vegetais da Caatinga Utilizadas pelas Abelhas Indígenas Sem Ferrão como Fonte de Recursos e Local de Nidificação. In: CONGRESSO BRASILEIRO DE EXTENSÃO UNIVERSITÁRIA, 1., 2002, João Pessoa. Anais... João Pessoa: Ed. Universitária, 2002.

PIMENTEL, J. V. F. Cultivo do cumaru (Amburana cearensis) em diversos sistemas de produção no semiárido. 2011. Tese (Doutorado em Engenharia Agrícola). Universidade Federal de Campina Grande, 2011.

PIMENTEL, J. V. F.; GUERRA, H. O. C. Irrigação, matéria orgânica e cobertura morta na produção de mudas de cumaru (Amburana cearensis) Agriambi, Campina Grande, v. 15, n. 9, p. 896-902, set. 2011.

PINTO, M. S. de C.et al. Modelo para estimativa da área foliar da maniçoba. Ciência Agronômica, Fortaleza, v. 38, n. 4, p. 391-395, out./dez. 2007. SILVA, F. de A. S.; AZEVEDO, C. A. V. de. A 
New Version of The Assistat-Statistical Assistance Software. In: WORLD CONGRESS ON COMPUTERS IN AGRICULTURE, 4., Orlando.

Proceedings... Orlando: American Society of Agricultural Engineers, 2006. p. 393-396.

SILVA, F. de A. S.; AZEVEDO, C. A. V. de. Principal Components Analysis in the Software Assistat-Statistical Attendance. In:WORLD CONGRESS ON COMPUTERS IN
AGRICUlTURE, 7., Reno. Proceedings... Reno: American Society of Agricultural and Biological Engineers, 2009.

TAIZ, L.; ZEIGER, E. Fisiologia vegetal. 3. ed. Porto Alegre: Artmed, 2004.

TATAGIBA, S. D. et al. Comportamento fisiológico de dois clones de Eucalyptus na época seca e chuvosa. Cerne, Lavras, v. 13, n. 2, p. 149-159, abr./jun. 2007. 